\title{
Modeling of Hydrogen Production in an Alkaline Electrolyser System Connected with a Solar Photovoltaic Panel or a Wind Turbine: Case Study; Douala-Cameroon
}

\author{
Eddy R. Essoumam Nkanga, Didier Zeh Ndoh, Joachim Ntonda, Arnaud Nanfak, \\ Maurice Thésée Mekouebe, Frédéric Lontsi
}

Laboratory of Energy, Materials, Modelling and Methods, National Higher Polytechnic School of Douala, University of Douala*, Cameroon

Email: edrod1717@gmail.com, didierndohze@yahoo.fr, Joachim_ntonda@yahoo.com, nanfak.arnaud@yahoo.fr,mauricethesee@yahoo.fr, lontsi@yahoo.fr

How to cite this paper: Nkanga, E.R.E., Ndoh, D.Z., Ntonda, J., Nanfak, A., Mekouebe, M.T. and Lontsi, F. (2021) Modeling of Hydrogen Production in an Alkaline Electrolyser System Connected with a Solar Photovoltaic Panel or a Wind Turbine: Case Study; Douala-Cameroon. Journal of Power and Energy Engineering, 9, 1-18.

https://doi.org/10.4236/jpee.2021.910001

Received: June 30, 2021

Accepted: October 10, 2021

Published: October 13, 2021

Copyright $\odot 2021$ by author(s) and Scientific Research Publishing Inc. This work is licensed under the Creative Commons Attribution International License (CC BY 4.0).

http://creativecommons.org/licenses/by/4.0/

\begin{abstract}
This article is in the field of research into the storage of renewable energy production. One of the main obstacles to the rapid development of renewable energies is the storage of the energy produced at low cost and with good efficiency. The production of hydrogen from renewable energies is a promising solution. The present work evaluates the potential of hydrogen production by electrolysis from solar photovoltaic and wind renewable energies in the city of Douala in Cameroon. The methodological approach used is based on the semi-empirical modelling approach of an alkaline electrolyser associated with the solar panel or the wind turbine. The simulation results obtained on the MATLAB/Simulink platform show that the average hydrogen production potential is estimated at $0.55 \mathrm{Nm}^{3} / \mathrm{h}$ for a PV panel supply, which corresponds to average energy efficiency of $70 \%$, and at $0.675 \mathrm{Nm}^{3} / \mathrm{h}$ for a wind turbine supply, which corresponds to average energy efficiency of $84 \%$. These results show the need to promote this technology, whose efficiency can be improved depending on the choice of site.
\end{abstract}

\section{Keywords}

Renewable Energies, Storage, Electrolyser, Hydrogen

\section{Introduction}

The processes for obtaining hydrogen are multiple and varied. They range from *PO Box: 2701 of university of Douala. 
carbon methanization to steam reforming passing through electrolysis. These processes are classified according to the amount of carbon dioxide $\left(\mathrm{CO}_{2}\right)$ released into the environment, through chemical, bioprocess and renewable processes. Compared to hydrogen by steam reforming, hydrogen production by water electrolysis is still low. To reduce carbon dioxide $\left(\mathrm{CO}_{2}\right)$ emissions and become independent of fossil fuel sources, the share of hydrogen produced from renewable energy sources must be significantly increased in the coming decades [1]. Indeed, Hydrogen is considered a promising energy carrier for a sustainable future when produced using renewable energy [2]. In general, hydrogen is a molecular compound in the gaseous state at standard temperature and pressure (STP). It is present as traces $(0.5 \mathrm{ppm})$ in the atmosphere and less dense than air. The production of hydrogen by electrolysis of water consists of an electrochemical reaction, which decomposed water into hydrogen and oxygen. It is made possible by the passage of a direct current through two electrodes immersed in a liquid or solid electrolyte. Among the renewable energies that can be used, solar photovoltaic and wind are the most promising sources because of their worldwide availability. Many governments have provided the necessary incentives to promote the use of renewable energy, encouraging a more decentralized approach to energy supply systems [3]. Also, the nations of the world have set themselves the goal to reducing their greenhouse gas (GHG) emissions and keeping global warming below $2^{\circ} \mathrm{C}$ by 2100 . These nations have come together in a federation known as the COP [4]. In Cameroon, for example, legislation adopted in 2011 under the name of the General Electricity Code promotes the development of renewable energy.

The photovoltaic panel is an association of individual solar cells, its Intensity-Voltage I-V characteristic is directly linked to the characteristic of the basic solar cell. The literature review presents some basic knowledge of PV module modeling [5]. In the work of Koumi et al. [6], a review of four of the most commonly used models for estimating the performance of PV modules in a Sahelian Sudanese climate was conducted; it was found that the single diode model performed well. The connection of PV panel atelectrolyser has been studied in Tokyo, Japan, and a design method for a solar hydrogen energy system, providing the most cost-effective hydrogen production, has been developed [7]. Similar studies were studied in Beijing, China, and a dynamic model was developed to simulate the system performance [8]. The work of Ursùa et al. [9], presents the complete experimental characterization of the operation of a $1 \mathrm{Nm}^{3}$ alkaline water electrolyzer under the conditions of a stand-alone wind power system and a PV panel based power system. This work resulted in average energy efficiency of about $78 \%$. The different observations in the literature lead to the question of the efficiency of feeding an electrolyser through a renewable energy source. In other words, how to interpret the hydrogen production efficiency of an electrolyser coupled to a renewable source.

In this work, the potential of hydrogen production by electrolysis from solar photovoltaic and wind renewable energies in the city of Douala in Cameroon is 
evaluated based on the climatic and atmospheric conditions at the year 2020.

The rest of this paper is organized as follows: After describing the system in section 2, mathematical modelling of the components is performed taking into account the environmental conditions of the study site is given in section 3 . Subsequently, simulation results using MATLAB/Simulink software are analyzed in Section 4. Finally, Section 5 concludes the paper.

\section{Description of the System}

The description of the simulated protocol is based on three aspects. The input of the electrolyzer through solar radiation or wind speed is the primary energy source; in the center of the process of electrolysis by an electrolyser, the output is a quantity of renewable hydrogen produced. Solar irradiation is captured by photovoltaic cells which transform the radiation into electricity by means of photons, composed of semiconductor materials arranged in series and in parallel (mostly silicon layer). The electrical energy obtained is used to power the alkaline electrolyser. The electrolyser supplied with pure water can thus dissociate the water molecule $\left(\mathrm{H}_{2} \mathrm{O}\right)$ into hydrogen molecule $\left(\mathrm{H}_{2}\right)$ and dioxygen molecule $\left(\mathrm{O}_{2}\right)$. These molecules are stored in the hydrogen and oxygen tubes or tanks. The wind speed generates the rotation of the wind turbine which, through its rotor, transforms the mechanical energy into electrical energy. The voltage obtained is alternating and needs to be transformed into direct voltage by means of a converter $(\mathrm{AC} / \mathrm{DC})$ to feed the electrolyser which works in direct current. The model of our energy system can be seen in Figure 1.

The methodological approach can be summarized in a set of modeling of the components of our energy system followed by a simulation of hydrogen production.

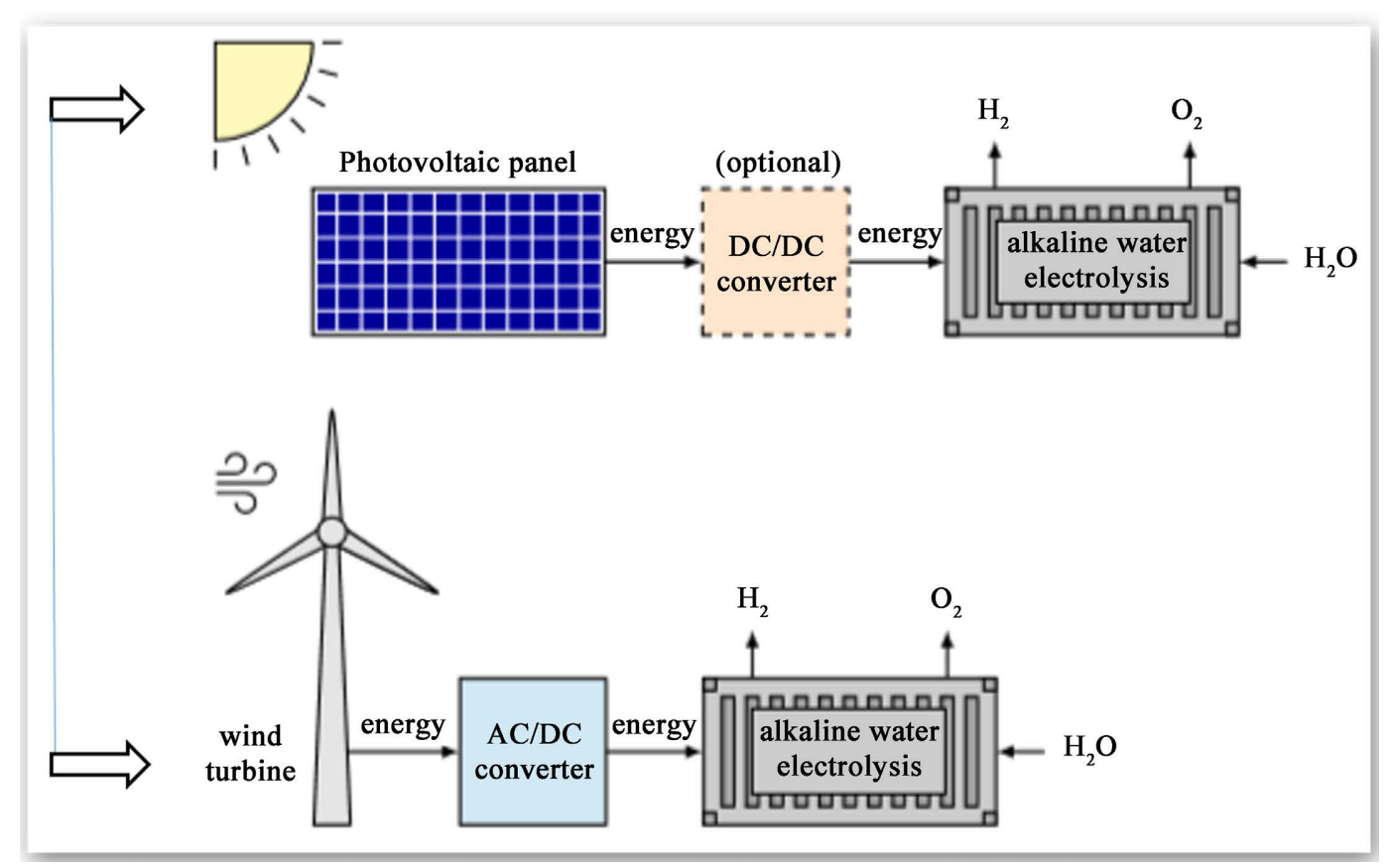

Figure 1. Alkaline water electrolysis powered by solar or wind energy [10]. 


\section{Modeling of the Components Determinant to the Electrolysis of Water}

\subsection{Modeling of the Electrolyzer}

The electrolyzer is the central element of our renewable hydrogen production system. The choice of the alkaline technology is based on a set of criteria that can be summarized in Figure 2.

It appears that the alkaline technology at high temperature and high pressure (called advanced technology) currently has the best yields for current densities lower than $1 \mathrm{~A} / \mathrm{cm}^{2}$. In addition, the absence of corrosive liquids ( $\mathrm{KOH}$ for alkaline electrolysis) has favored its use in our study [11].

\section{Mathematical model for the characterization of an electrolyser}

This model developed by Alhassan Salami, et al. [12], derives from the thermodynamic model of Ulleberg.

$$
\begin{gathered}
\mathrm{H}_{2} \mathrm{O}_{(1)}+\text { electrical energy } \rightarrow \mathrm{H}_{2(\mathrm{~g})}+\frac{1}{2} \mathrm{O}_{2(\mathrm{~g})} \\
\Delta G=z F V_{\text {rev }} \\
V_{\text {rev }}=\frac{\Delta G}{z F} \\
V_{\text {rev }}=\frac{237.2 \mathrm{~kJ} / \mathrm{mole}}{2 \times 96485 \mathrm{C} / \mathrm{mole}}=1.229 \mathrm{~V}
\end{gathered}
$$

$\Delta G$ : Gibbs Energy;

$z$. Number of electrons;

F: Faraday's constant.

The cell voltage is given by the relation

$$
V_{\text {cell }}=V_{\text {rev }}+V_{\text {act }}+V_{\text {ohm }}
$$

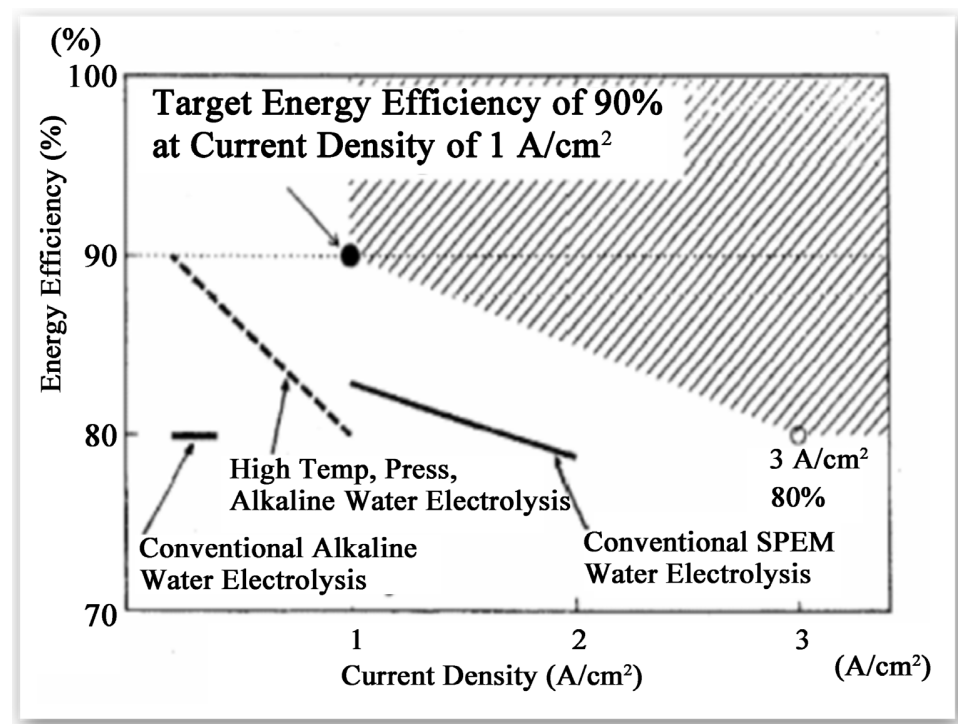

Figure 2. Efficiency of the different electrolyser technologies [12]. 


$$
\begin{gathered}
V_{\text {act }}=s \log \left(\frac{t_{1}+\frac{t_{2}}{T}+\frac{t_{3}}{T^{2}}}{A} I+1\right) \\
V_{\text {ohm }}=\frac{r_{1}+r_{2} T}{A} I
\end{gathered}
$$

where $r$ ohmic resistance; $s, t$. overvoltage coefficient.

The Oystein Ulleberg equation

$$
V=V_{\text {rev }}+s \log \left(\frac{t_{1}+\frac{t_{2}}{T}+\frac{t_{3}}{T^{2}}}{A} I+1\right)+\frac{r_{1}+r_{2} T}{A} I
$$

Based on Faraday's law with the coefficient

$$
\eta_{F}=\frac{\left(\frac{I}{A}\right)^{2}}{f_{1}+\left(\frac{I}{A}\right)^{2}} f_{2}
$$

The hydrogen production rate is expressed according to the relation

$$
\dot{n}_{\mathrm{H}_{2}}=\eta_{F} \frac{\eta_{c} I}{z F}
$$

The production rate of hydrogen expressed $\mathrm{inNm}^{3} / \mathrm{h}$

$$
Q=\dot{n}_{\mathrm{H}_{2}} \times 3600 \times 0.022414 .
$$

To apply the Ulleberg model, the electrolyser choose in the case of this study has been developed by hydrogen system and the characteristics can be found in Table 1 .

The estimation of the hydrogen production potential requires the characterization of the electrolyser device. In this sense, we have chosen the alkaline electrolyser of the manufacturer Hydrogen system, whose literature has exploited this technology, in particular in the thesis work done by Julien LABBE.

The $3.6 \mathrm{~kW}$ electrolyser (Hydrogen Systems, Belgium) consists of 16 cells in series of $300 \mathrm{~cm}^{2}$, advanced alkaline technology, "zero gap" geometry. The electrolyte is $30 \%$ mass concentrated potassium hydroxide. The maximum operating pressure is 10 bar. The nominal point of the electrolyser is $29 \mathrm{~V}-120 \mathrm{~A}$ at $72^{\circ} \mathrm{C}$. The gas production at $120 \mathrm{~A}$ is $0.8 \mathrm{Nm}^{3} / \mathrm{h}$ ( $99.7 \%$ faradic efficiency). The periphery of the electrolyser consists of 2 communicating vessels, called separators, because they allow the separation of the produced gases and the electrolyte. The separators are placed above the cells and are partly filled with liquid electrolyte (KOH 30\%), the electrolyte circulates naturally from the separators to the cells, by the "gas lift" effect: the gases produced by the cells rise in the separators and cause the electrolyte to circulate [11].

The modeling phase of the electrolyser is thus completed, leaving room for the feeding phase, which is an essential link in the dislocation of the water molecule. 
This is all the more important since our electrolyser is powered by renewable energy sources such as solar panels.

\subsection{Modeling of the Solar PV Panel}

The panel modeled is a panel marketed by PHOTOWATT as PW6-110 made of $6 \times 12$ polycrystalline cells of $150 \mathrm{~mm} \times 150 \mathrm{~mm}$ with a silicon nitride anti-reflection layer and their characteristics are presented in Table 2.

By connecting a variable electrical charge, we can determine the current-voltage (I-V) characteristic of the cell and its variation according to solar irradiation and temperature. The photocells do not impose a current or a fixed voltage but it is

Table 1. Constant parameters of the electyrolyser hydrogen system [13].

\begin{tabular}{|c|c|c|c|c|}
\hline Constant parameters & Symbols & & Units & Values \\
\hline Reversible voltage & $V_{\text {rev }}$ & & $\mathrm{V}$ & 1.229 \\
\hline The area of the electrode & $A$ & & $\mathrm{~m}^{2}$ & 0.25 \\
\hline Faraday's constant & $F$ & & $\mathrm{C} / \mathrm{mol}$ & 96485 \\
\hline Number of electrons & $Z$ & & & 2 \\
\hline Number of cells & $n$ & & & 1 \\
\hline \multirow[t]{2}{*}{ Coefficient of overvoltage of the electrode } & $s$ & & $\mathrm{~V}$ & 0.185 \\
\hline & $t_{1}$ & & $\mathrm{~A}^{-1} \mathrm{~m}^{2}$ & 1.002 \\
\hline \multirow[t]{2}{*}{ Coefficient of overvoltage of the electrode } & $t_{2}$ & & $\mathrm{~A}^{-1} \mathrm{~m}^{2 \circ} \mathrm{C}$ & 8.424 \\
\hline & $t_{3}$ & & $\mathrm{~A}^{-1} \mathrm{~m}^{2 \circ} \mathrm{C}$ & 247.3 \\
\hline \multirow{2}{*}{$\begin{array}{l}\text { Parameters related to the ohmic } \\
\text { resistance of the electrolyzer }\end{array}$} & $r_{1}$ & & $\Omega \mathrm{m}^{2}$ & $8.05 \mathrm{e}^{-5}$ \\
\hline & $r_{2}$ & & $\Omega \mathrm{m}^{2} \cdot{ }^{\circ} \mathrm{C}^{-1}$ & $-2.5 \mathrm{e}^{-7}$ \\
\hline Parameters & Units & & & \\
\hline Temperature & ${ }^{\circ} \mathrm{C}$ & 40 & 60 & 80 \\
\hline$f_{1}$ & $\mathrm{~mA}^{2} \mathrm{~cm}^{-4}$ & 150 & 200 & 250 \\
\hline$f_{2}$ & $0 \ldots \ldots 1$ & 0.990 & 0.985 & 0.980 \\
\hline
\end{tabular}

Table 2. Characteristics of the PW6-110 panel [14].

\begin{tabular}{ccc}
\hline PW6-110 & Units & Configuration $12 \mathrm{~V}$ \\
\hline Typical power & $\mathrm{W}$ & 110 \\
Minimum power & $\mathrm{W}$ & 106 \\
Voltage attypical power & $\mathrm{V}$ & 17.2 \\
Currentattypical power & $\mathrm{A}$ & 6.4 \\
Short circuit current & $\mathrm{A}$ & 6.9 \\
Open circuit voltage & $\mathrm{V}$ & 21.17 \\
Maximum circuit voltage & $\mathrm{V}$ & $770 \mathrm{~V} \mathrm{DC}$ \\
Temperature coefficient & $\alpha=-2085 \mathrm{~mA} /{ }^{\circ} \mathrm{C} ; \beta=-79 \mathrm{mV} /{ }^{\circ} \mathrm{C} ; \gamma^{\mathrm{P} / \mathrm{P}}=-0.43 \% /{ }^{\circ} \mathrm{C}$ \\
Power specification at $1000 \mathrm{~W} / \mathrm{m}^{2}, 25^{\circ} \mathrm{C} \mathrm{AM} 1.5$ & \\
\hline
\end{tabular}


the load which will determine it in a curve $\mathrm{I}(\mathrm{V})$ which depends on the temperature and the flux at the point of operation. This curve can be modeled according to Equation (12) [15].

$$
I=I_{p h}-I_{0}\left(\mathrm{e}^{\frac{V+R_{s} I}{n k T / Q}}-1\right)-\frac{V+R_{s} I}{R_{s h}}
$$

$I_{0}$ : saturation current of the diode. $I_{p h}$ : photo generated current. $k$. Boltzmann's constant $\left(1.381 \times 10^{-23} \mathrm{~J} / \mathrm{K}\right.$.), $n$ : avalanche exponent. $Q$ : elementary charge 1.602 $\times 10^{-19}$ C. $R_{s h}:$ parallel (or shunt) resistance. $R_{s}$ : series resistance. T: absolute temperature in ${ }^{\circ} \mathrm{K}$.

Solar PV panels are highly dependent on the level of sunshine in the locality. In order to predict the size of the panels, an analysis of the average level of sunshine is determined. This analysis is done by determining the global solar irradiation.

\section{Angstrom's models for determining the global solar irradiation}

Linear model:

$$
\frac{H}{H_{o}}=a+b\left(\frac{S}{S_{o}}\right)
$$

Non-linear or polynomial model:

$$
\frac{H}{H_{o}}=a+b\left(\frac{S}{S_{o}}\right)+\left(\frac{S}{S_{o}}\right)^{2}+\left(\frac{S}{S_{o}}\right)^{3}+\cdots
$$

where $a, b, c, d$ are correlation coefficients referred to as Angstrom constants and are empirical [16]. $H$ and $S$ are respectively the measurements of the average value of the monthly global irradiation $\left(\mathrm{MJ} / \mathrm{m}^{2}\right)$ and the average duration of the sun (h). $H_{o}$ and $S_{o}$ are determined from mathematical equations.

$$
\begin{gathered}
H_{o}=\frac{24 \times 3600}{\pi} G_{o}\left(\cos \varphi \cdot \cos \delta \cdot \sin \omega_{s}+\frac{\pi}{180} \omega_{s} \cdot \sin \varphi \cdot \sin \delta\right) \\
G_{o}=I_{s c}\left(1+0.034 \cos \left(\frac{360 \times n_{\text {jour }}}{365.25}\right)\right)
\end{gathered}
$$

$I_{s c}$ equal solar constant à $1367 \mathrm{KW} / \mathrm{m}^{2} ; \delta$ : Declination; $\omega_{s}$ : hour angle; $\varphi$ : latitude of the site.

Concerning the city of Douala, Angstrom's coefficients are indicated in Table 3.

$$
\begin{gathered}
\delta=23.45 \sin \left(\frac{360\left(n_{\text {jour }}+284\right)}{365}\right) \\
\omega_{s}=\cos ^{-1}(-\tan \delta \cdot \tan \varphi) \\
S_{o}=\frac{2}{15} \omega_{s}
\end{gathered}
$$

Table 3. Regression coefficients obtained from Angstrom's models [16].

\begin{tabular}{ccccc}
\hline Villes & $\boldsymbol{a}$ & $\boldsymbol{b}$ & $\boldsymbol{c}$ & $\boldsymbol{D}$ \\
\hline Douala & -0.6034 & 5.9653 & -11.3126 & 7.3260 \\
\hline
\end{tabular}


The electrolyser can be powered by a PV solar panel or by a wind turbine. The latter is the subject of this part of our study.

\subsection{Wind Turbine Modeling}

Since energy from photovoltaic cells is only available during the day, wind power is another important energy source for renewable hydrogen production. For the implementation of conventional wind turbines, an AC/DC converter is essential. The efficiency of an AC/DC converter is around 90\% [17].

To determine the power output of the wind turbine, the exact wind speed at the height of the wind turbine rotor must be known. Often, the wind speed is measured at sea level or at special measuring facilities with a defined height of about $4 \mathrm{~m}$, which is significantly lower than the height of a wind turbine, about $12 \mathrm{~m}$ for our estimation [18] [19] [20] [21]. Therefore, the measured data must be corrected to the desired height by Equation (20).

The wind speed $V_{\text {wind }}$ at height $Z_{\text {wind }}(12 \mathrm{~m})$ can be determined from the measured wind speed $V_{\text {wind,ref }}$ at height $Z_{\text {wind,ref }}(4 \mathrm{~m})$ in combination with the roughness of the ground $Z_{0}(1)$ [17].

$$
V_{\text {wind }}=V_{\text {wind,ref }} \frac{\ln \left(\frac{Z_{\text {wind }}}{Z_{0}}\right)}{\ln \left(\frac{Z_{\text {wind,ref }}}{Z_{0}}\right)}
$$

To obtain the power output of a wind turbine $P_{\text {turbine, }}$ the theoretical wind power $P_{\text {wind }}$ must first be calculated using equations (21). Therefore, the air density $\rho$ (from 1.22 to $1.3 \mathrm{~kg} / \mathrm{m}^{3}$ ), the area covered by the rotor blades $\mathrm{A}$, and the wind speed are required [18].

$$
P_{\text {wind }}=\frac{1}{2}\left(\rho A V_{\text {wind }}^{3}\right)
$$

The maximum wind power cannot be fully converted into electrical energy by the turbines. This circumstance is taken into account by applying the performance coefficient $C p$, which reduces the maximum achievable power. The actual power of the wind turbine results from the product of the wind power and the coefficient of performance as shown in Equation (22).

$$
P_{\text {turbine }}=P_{\text {wind }} \cdot C p
$$

Determining the correct coefficient of performance is a comprehensive research topic in itself, consisting of empirical correlations and computational fluid dynamics (CFD) simulation studies. Often, experimental data are used to fit correlations to measurements. An example of an equation for the coefficient of performance is shown in Equation (23) [18].

$$
C p=0.22\left(\frac{116}{\lambda i}-0.4 \beta-5\right)
$$

For the blade radius, a value of $2 \mathrm{~m}$ is assumed, which is a typical blade length for a wind turbine with a rated power of $10 \mathrm{Kw}$. The coefficient of performance 
of conventional wind turbines is limited to $C p=0.593$ [18].

\section{Numerical Method of Compilation}

The simulation was carried out on the basis of the equations presented in the methodological approach. The calculation programs were written in Matlab language. The data collected during the compilation can be summarized as follows.

Electrolyser

Input parameters: $\mathrm{f} 1=150 \mathrm{~mA} / \mathrm{cm}^{4} ; \mathrm{f} 2=0.99 \mathrm{~mA} / \mathrm{cm}^{4}$.

Solar panel

Input parameters: $\mathrm{Rsh}=57.14 ; \mathrm{Ns}=12 ; \mathrm{Np}=100 ; \mathrm{Sp}=0.15^{2} ; \mathrm{PCS}=39.41$;

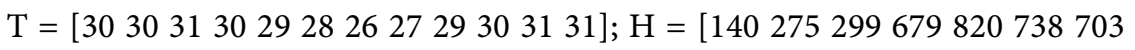

788600499252 50]; nday = [31 5990120151181212243273304334 365]; n1 $=16 ; \mathrm{A}=0.48$.

Solar flux

Input parameters: Angstrom coefficient table.

Wind turbine

Input parameters: Zwindref $=4$;

Vwindref $=\left[\begin{array}{lllll}3.060483871 & 3.556451613 & 3.286290323 & 3.116935484 & 3.14516129\end{array}\right.$

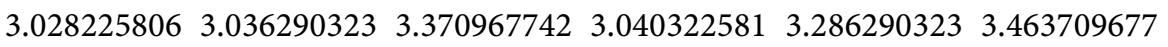

3.39516129];

$\mathrm{Zo}=1 ; \mathrm{Zwind}=12 ;$ rho $=1.22 ; \mathrm{A}=12.5 ; \mathrm{Cp}=0.5$.

\section{Simulation and Discussion}

It is based on the development of Equations (4) to (22). The energy efficiency of the overall system is subject to the influences of internal, environmental and geographical parameters.

\subsection{Influence of Current Density on Hydrogen Production}

From the methodological approach discussed, it follows descriptions and interpretations followed by graphical observations.

The implementation of Equations (9) and (10) on the software Matlab 2018 version allowed us to obtain the graph characterized by Figure 3.

The shape of the different curves and their positioning clearly express the relationship that exists between the current density, the hydrogen production and the temperature of the electrolyser. We can see that the hydrogen production increases with the current density in a linear way. However, the temperature does not have a significant impact on the hydrogen production rate.

From Equation (8), the curves of Figure 4 were obtained by simulation in Matlab. The evolution of the Faraday coefficient with the density shows a first phase of fast and linear growth of the Faraday coefficient corresponding to a current density between $[15 ; 25] \mathrm{mA} / \mathrm{cm}^{2}$; a second phase of moderate growth of the Faraday coefficient corresponding to a current density between [25; 50] 


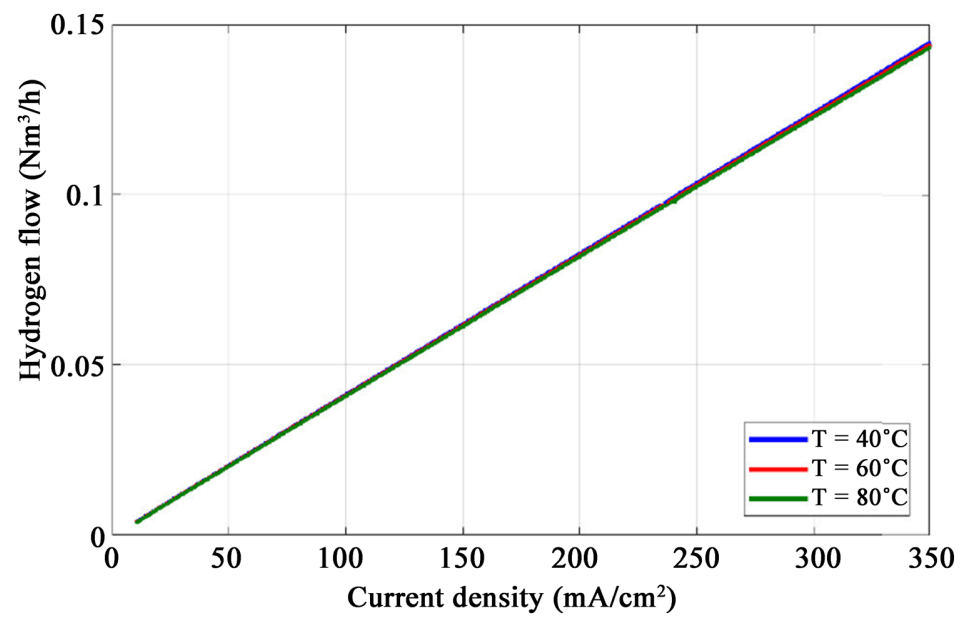

Figure 3. Influence of current density and temperature on hydrogen production.

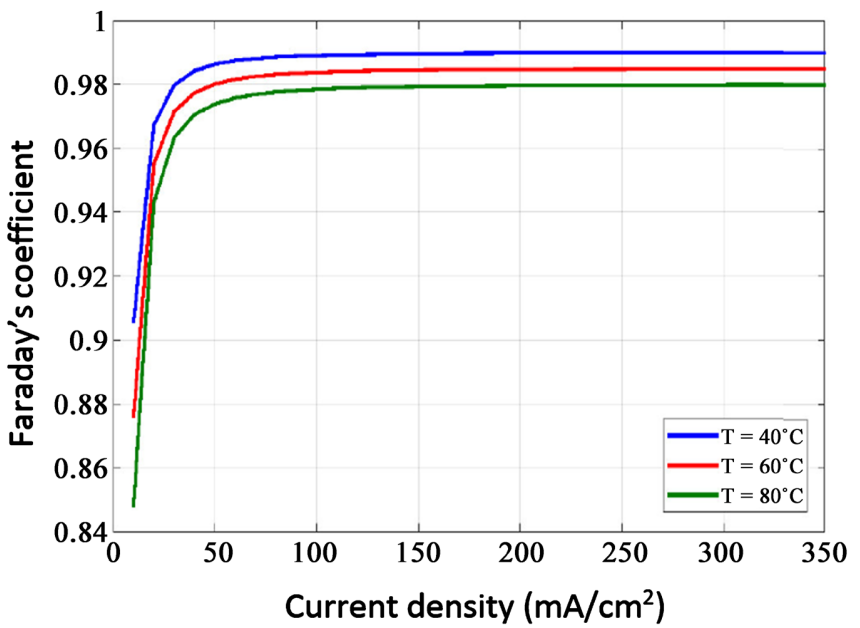

Figure 4. Influence of the current density and temperature on the Faraday's coefficient.

$\mathrm{mA} / \mathrm{cm}^{2}$; a third phase quasi stationary or phase of saturation of the Faraday coefficient for the current densities higher than $50 \mathrm{~mA} / \mathrm{cm}^{2}$. In addition, we note that the Faraday coefficient is inversely proportional to the temperature.

\subsection{Influence of Current Density and Temperature, on the Voltage of the Electrolyser Cells}

From Equation (7), it is obtained by numerical simulation on Matlab the characteristic curve. The voltage in the cell of the electrolyzer is proportional to the current density. Also at more than $150 \mathrm{~mA} / \mathrm{cm}^{2}$ the growth curve is linear and with a strong slope. The temperature on the other hand has a lesser influence on the cell voltage.

\subsection{Influence of the Cell Voltage on the Current Generated by the PV Panel}

The exploitation of Equation (12) allowed to highlight by simulation the curves of Figure 6. The current generated by the panel decreases with the cell voltage. 
For values of voltage between $[0 ; 10] \mathrm{V}$, we have a linear decrease with low slope of the current at a significant influence of the ambient temperature. At more than $10 \mathrm{~V}$ the current is a function of the voltage and the ambient temperature. The short-circuit current is not a function of temperature. On the other hand, the open circuit voltage is inversely proportional to the temperature.

The implementation of Equation (11) in the Matlab software has allowed highlighting the different curves of Figure 7. Contrary to the temperature, the solar flux is a major determinant of the efficiency of the solar panel and its characterization (intensity-voltage).

\subsection{Result of the Simulation in the City of Douala}

\subsubsection{Profile of the Solar Flux}

The exploitation of the Angstrom model, in particular Equations (13) to (19) for

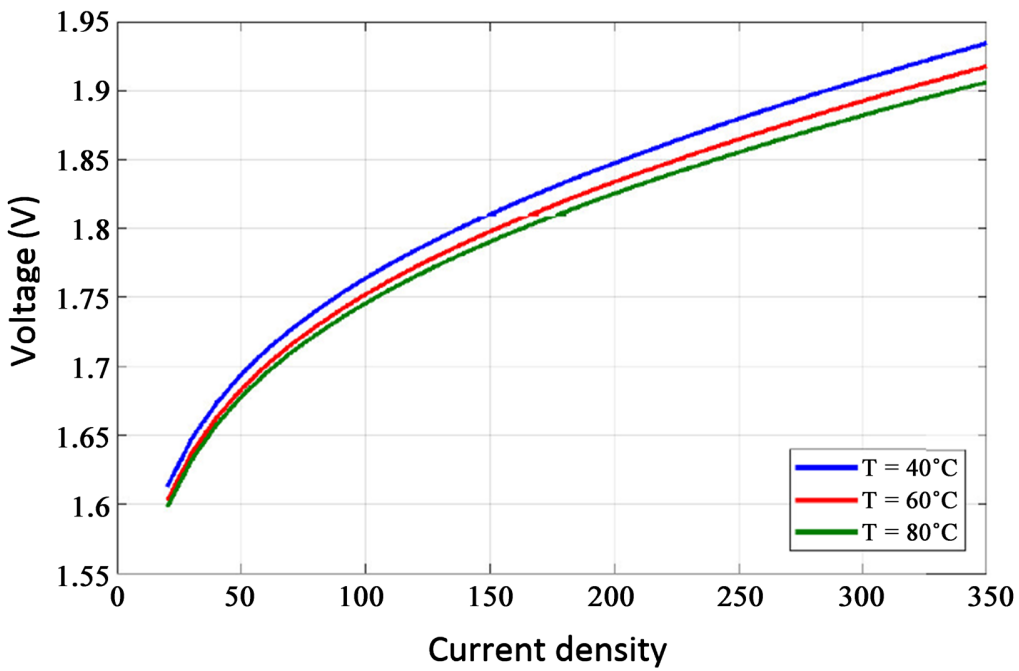

Figure 5. Influence of the temperature in the current density-voltage characteristic of the electrolyzer.

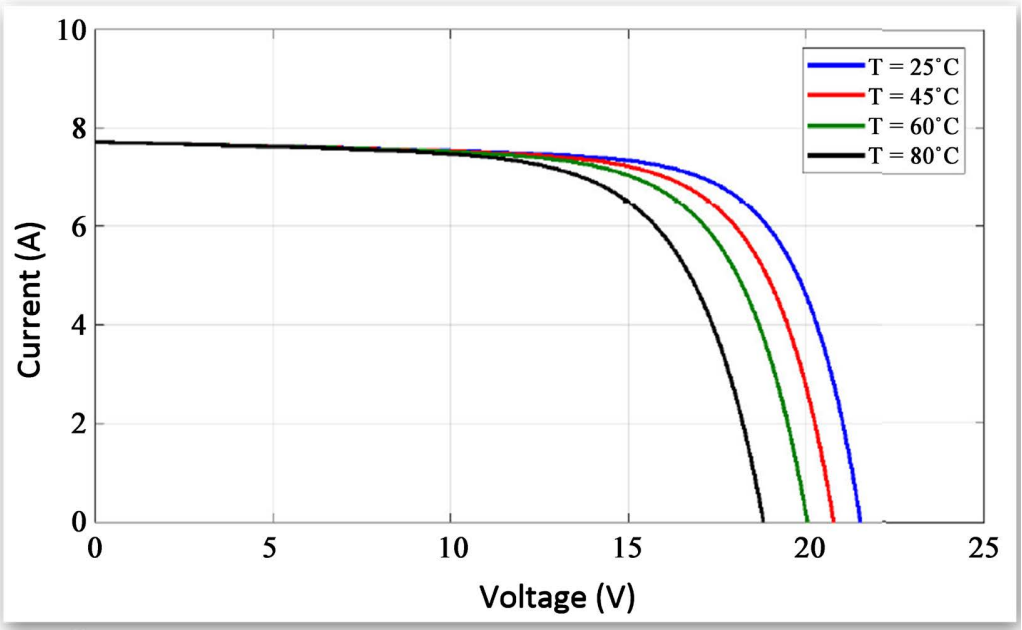

Figure 6. Influence of the temperature in the current-voltage characteristic of the panel. 
the determination of the solar flux from the data of the average duration of the sun per hour (see appendix) leads us to Figure 8. The analysis of this figure can be done in 03 periods. From January-March we observe a maximum solar flux reaching a value of $243 \mathrm{~W} / \mathrm{m}^{2}$ which can be justified by high average temperatures; From April-July and October-November we note a decrease in solar flux with a minimum value of $167 \mathrm{~W} / \mathrm{m}^{2}$ reached in August. This can be explained by a decrease in the average temperature during these months; September-October and November-December: we have an increase in solar flux with a maximum at $235 \mathrm{~W} / \mathrm{m}^{2}$.

\subsubsection{Profile of the Volume of Hydrogen Produced $\left(\mathrm{QH}_{2}\right)$}

The amount of hydrogen produced by water electrolysis powered by a wind turbine

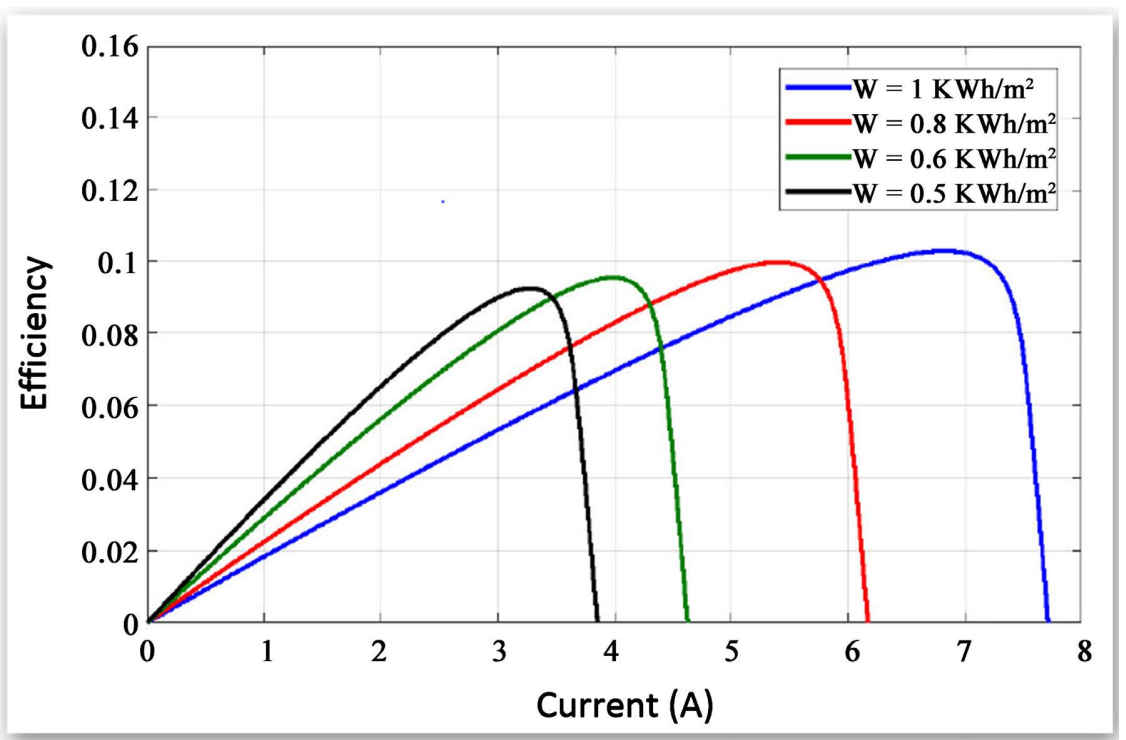

Figure 7. Efficiency of the panel with influence of the solar flux.

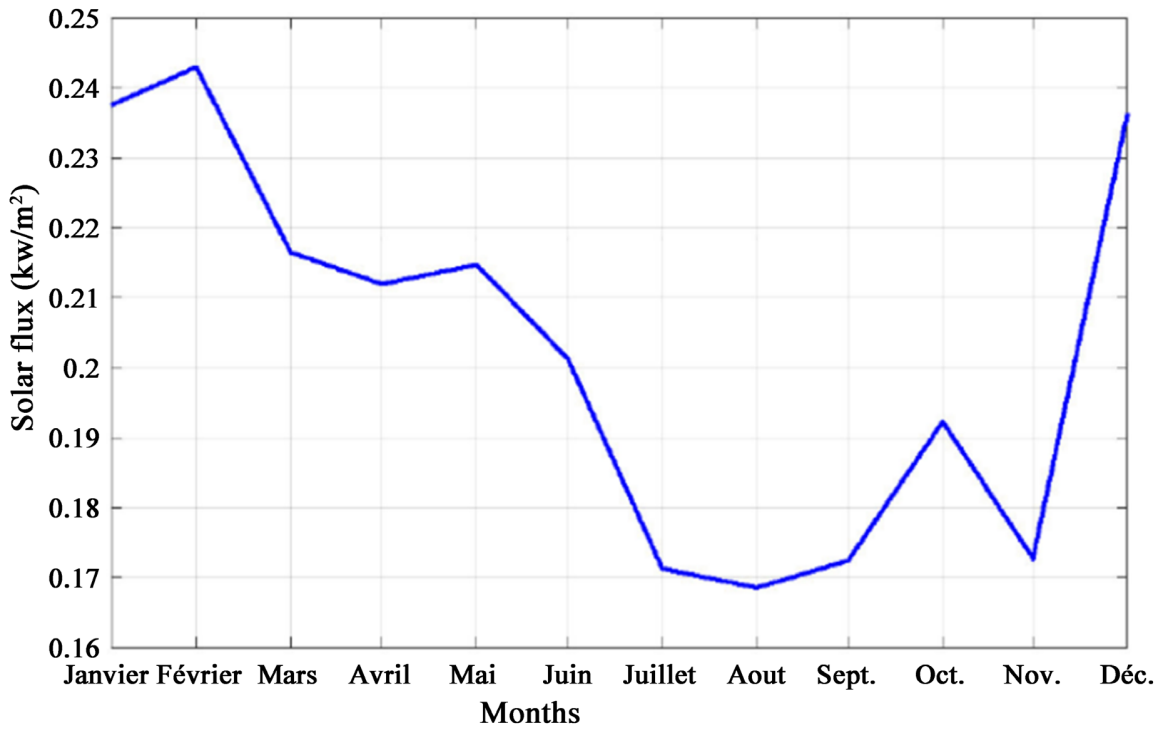

Figure 8. Monthly solar flux at Douala in 2020. 
is proportional to the power of the turbine. The latter is converted to DC when passing through an AC/DC converter. The acceptable voltage limits of our electrolyser being known, we can deduce the DC currents supplied to the electrolyser as a function of the power. From this principle, it becomes possible to estimate the hydrogen production rate. In our study framework, we have discussed the estimable monthly average predictions for the city of Douala. These predictions integrate the meteorological data (reference data), the wind speeds at the wind turbine, the estimated powers of the turbine and the quantities or volume of hydrogen potentially producible. Simulations were performed using the data cross-referenced to monthly averages over an annual period.

Figure 9 is a window of the simulation in Matlab software of the models mentioned in the methodology section. This window is filled with four curves whose similarities in the two-by-two paces can be seen.

The curve of the wind speed as a function of the month and the curve of the wind speed at the wind turbine. The first curve is derived from a monthly

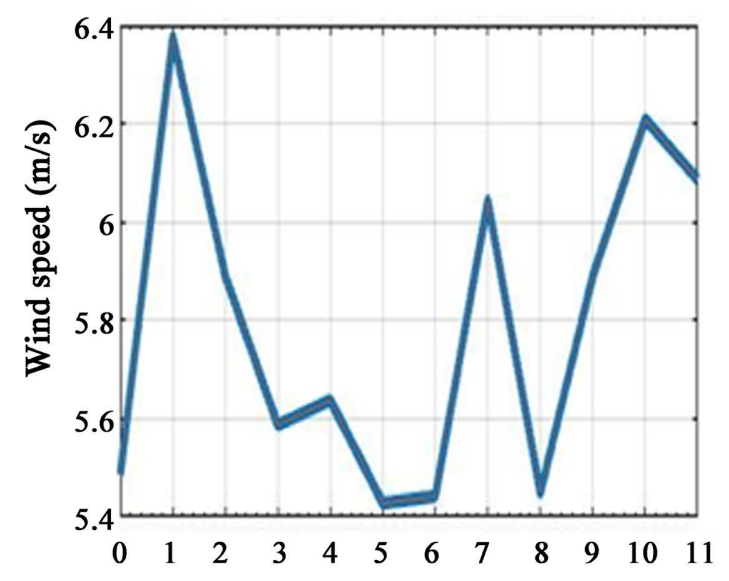

Months of the year

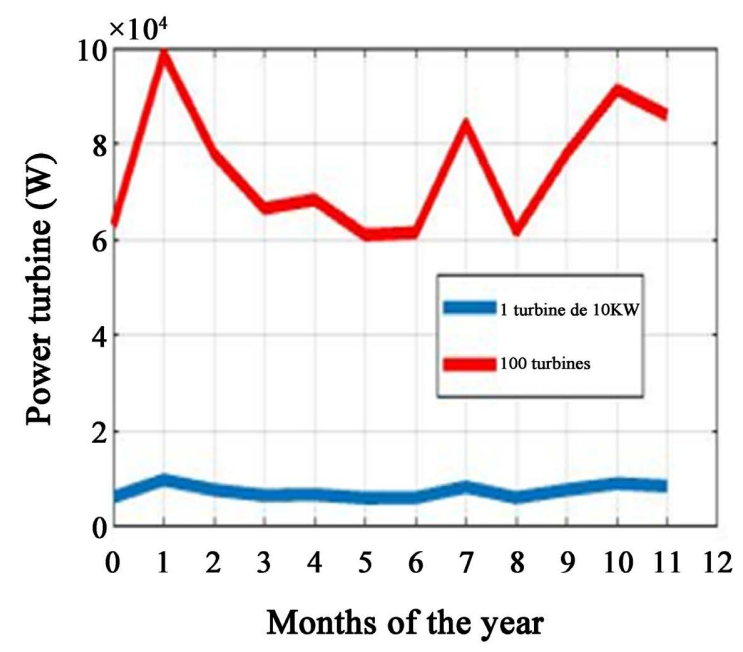

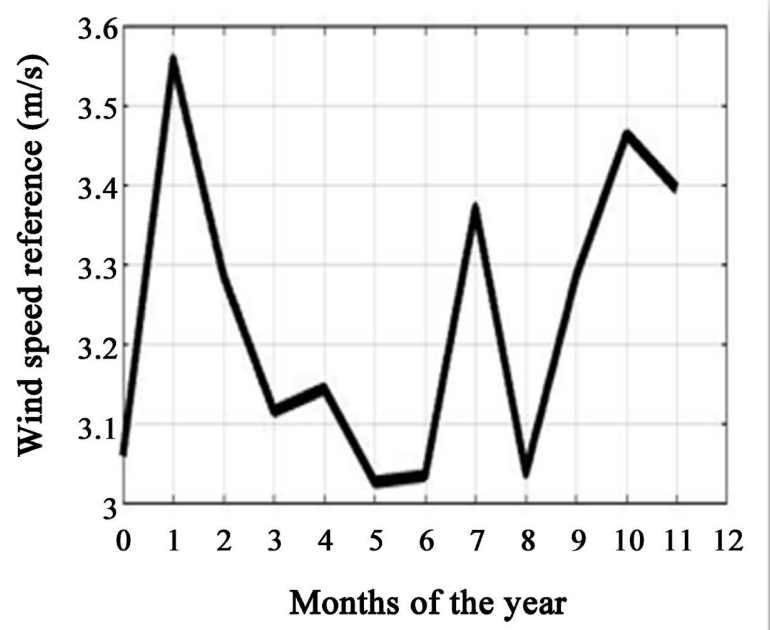

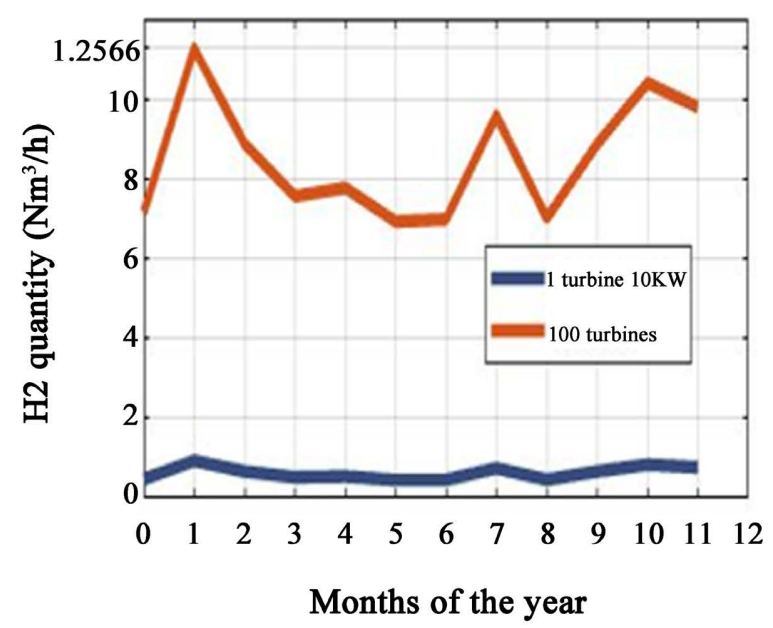

Figure 9. Profile of wind speed and amount of hydrogen produced. 
compilation of meteorological data provided by an approved center in the city of Douala (i.e. the Regional Delegation of the Ministry of Transport) followed by a simulation in the Matlab software. From this curve, it appears that the average monthly difference between the windiest month and the least windy month is less than $0.6 \mathrm{~m} / \mathrm{s}$; a standard deviation of about 0.1 and a maximum of less than $3.6 \mathrm{~m} / \mathrm{s}$. These parameters indicate a regular distribution of wind in the locality. However, the wind speeds are only usable for wind turbines with a medium power rating (around one kilowatt).

The wind speed curve at the wind turbine as a function of month is a function of the reference wind speed as described in Equation (20) in the methodology section. It can be seen that the higher the site of the wind turbine, the higher the wind speed and the lower the ground roughness. In our case, at an altitude of 12 $\mathrm{m}$, the monthly average wind speed is between $5.4 \mathrm{~m} / \mathrm{s}$ and $6.4 \mathrm{~m} / \mathrm{s}$.

The curves of the wind turbine power versus month are functions of the wind speed as shown in Equation (21). The blue curve as seen in the legend is the characteristic curve of wind power versus month for a turbine of nominal power $10 \mathrm{KW}$. From this figure, it emerges a statement of turbine power between 6.5 $\mathrm{kW}$ and $9 \mathrm{kw}$. The size of the wind turbine chosen, the site for the simulation in Douala allows the turbine to operate around its nominal point. The red curve is the estimated monthly power of a turbine field of 100 wind turbines. It should be noted that in this study a simplifying hypothesis was adopted which allows us to deduce that the total power of the site is the sum of the power generated by each wind turbine that constitutes the site.

The curves for the estimated monthly hydrogen quantity are functions of the wind turbine power and, in turn, of the wind speed. From the simulation of Equation (22) in Matlab we can obtain the above graph. It can be seen that for a wind turbine with a nominal power of $10 \mathrm{KW}$, placed at an altitude of $12 \mathrm{~m}$ (equivalent to an $\mathrm{R}+3$ building of the NHPSD), in the meteorological conditions of the city of Douala-Cameroon; connected to an alkaline electrolyzer described above. The potential for renewable hydrogen production per hour and per month can be estimated to be in the order of $0.5 \mathrm{Nm}^{3} / \mathrm{h}$ to $1 \mathrm{Nm}^{3} / \mathrm{h}$; with an average of $0.75 \mathrm{Nm}^{3} / \mathrm{h}$. The energy of the wind turbine with a nominal power of $10 \mathrm{KW}$ goes through an AC/DC converter whose efficiency is about $90 \%$. Hence the real quantities of hydrogen produced will be between $0.45 \mathrm{Nm}^{3} / \mathrm{h}$ and 0.9 $\mathrm{Nm}^{3} / \mathrm{h}$ with an average of $0.675 \mathrm{Nm}^{3} / \mathrm{h}$.

The evolution of this curve suggests production peaks in January, July and October. The strong correlation between the hydrogen production and the turbine power allows us to deduce that these months correspond to the windiest months of the year.

The orange curve is the estimated monthly hydrogen production potential for a field of 100 wind turbines. As for the power, a simplifying hypothesis has been adopted to deduce that the total amount of hydrogen production of the wind field collected at the electrolyzer is the sum of the quantities generated by each wind turbine that constitutes the site. 
The simulation of renewable hydrogen production in Douala by an alkaline electrolyser powered by wind turbine (s) presented above, it is up to us to make the same estimation when our electrolysis is powered by solar PV panel.

The amount of hydrogen produced can be estimated by the relationship stated in the methodology. Figure 10 shows a hydrogen rate that oscillates between 0.46 and $0.67 \mathrm{Nm}^{3} / \mathrm{h}$, values respectively reached during the months of August and February. These months correspond respectively to the least and the most sunny month. The amount of hydrogen produced is itself a function of the current density.

\section{Conclusion}

The modeling of hydrogen production by electrolysis fueled by renewable sources has been carried out. Based on mathematical and semi-empirical models in the geographical and environmental context of the city of Douala. It was shown that the average annual production rate of hydrogen is $0.55 \mathrm{Nm}^{3} / \mathrm{h}$ for a PV power supply; $0.675 \mathrm{Nm}^{3} / \mathrm{h}$ for a wind power supply. This means energy efficiencies of $70 \%$ and $84 \%$ of the electrolyser operation respectively. The differences in efficiency observed compared to the study of Ursùa, et al. are respectively $8 \%$ for the solar PV system and $+6 \%$ for the wind turbine system. These differences can be explained by the periods of observation which are on the one hand daily for the work of Ursùa, et al.; monthly within the framework of this work and by differences in meteorological conditions. With the different profiles of renewable hydrogen production having been observed, a perspective of coupling of sources can be considered. To do so, some assumptions must be made beforehand. The hydrogen produced needs to be stored in order to be used as an energy source. Moreover, in this work, the security and normative aspects

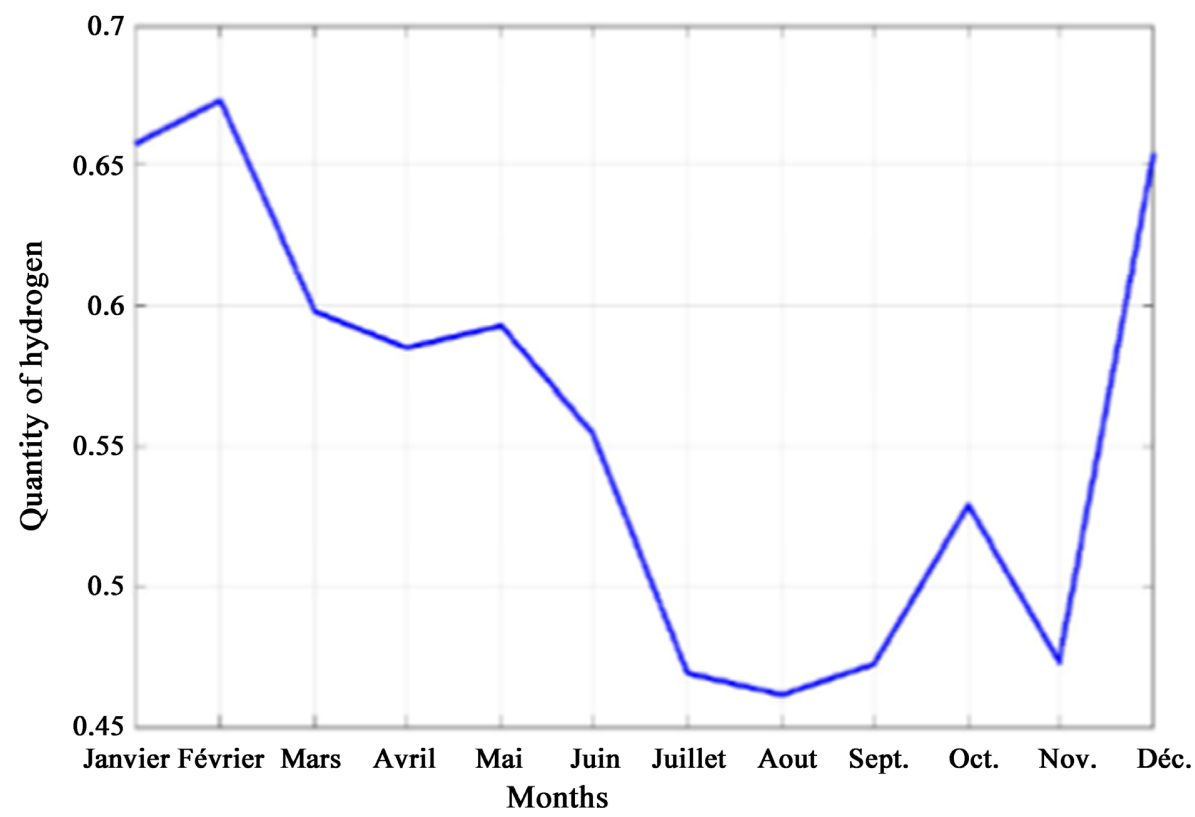

Figure 10. Profile of the amount of Hydrogen. 
related to the production of hydrogen have not been addressed, as well as the investment cost of such an energy system.

\section{Conflicts of Interest}

The authors declare no conflicts of interest regarding the publication of this paper.

\section{References}

[1] Mraoui, A., Benyoucef, B. and Hassaine, L. (2018) Experiment and Simulation of Electrolytic Hydrogen Production: Case Study of Photovoltaic-Electrolyzer Direct Connection. International Journal of Hydrogen Energy, 43, 3441-3450. https://doi.org/10.1016/j.ijhydene.2017.11.035

[2] Brauns, J. and Turek, T. (2020) Alkaline Water Electrolysis Powered by Renewable Energy: A Review. Processes, 8, 248. https://doi.org/10.3390/pr8020248

[3] Jaralikar, S.M. and Aruna, M. (2011) Case Study of a Hybrid (Wind and Solar) Power Plant. Telkomnika, 9, 19.

[4] Lal, R. (2016) Beyond COP 21: Potential and Challenges of the "4 per Thousand" Initiative. Journal of Soil and Water Conservation, 71, 20A-25A. https://doi.org/10.2489/jswc.71.1.20A

[5] Woyte, A., Nijs, J. and Belmans, R. (2003) Partial Shadowing of Photovoltaic Arrays with Different System Configurations: Literature Review and Field Test Results. Solar Energy, 74, 217-233. https://doi.org/10.1016/S0038-092X(03)00155-5

[6] Simon, K.N., Donatien, N. and Inoussah, M.M. (2012) Comparison of Predictive Models for Photovoltaic Module Performance under Tropical Climate. Telkomnika, 10, 245-256. https://doi.org/10.12928/telkomnika.v10i2.783

[7] Tani, T., et al. (2000) Optimization of Solar Hydrogen Systems Based on Hydrogen Production Cost. Solar Energy, 68, 143-149. https://doi.org/10.1016/S0038-092X(99)00061-4

[8] Su, Z., et al. (2014) Optimization and Sensitivity Analysis of a Photovoltaic-Electrolyser Direct-Coupling System in Beijing. International Journal of Hydrogen Energy, 39, 7202-7215. https://doi.org/10.1016/j.ijhydene.2014.02.136

[9] Ursúa, A., et al. (2013) Stand-Alone Operation of an Alkaline Water Electrolyser Fed by Wind and Photovoltaic Systems. International Journal of Hydrogen Energy, 38, 14952-14967. https://doi.org/10.1016/j.ijhydene.2013.09.085

[10] Khalilnejad, A. and Riahy, G. (2014) A Hybrid Wind-PV System Performance Investigation for the Purpose of Maximum Hydrogen Production and Storage Using Advanced Alkaline Electrolyzer. Energy Conversion and Management, 80, 398-406. https://doi.org/10.1016/j.enconman.2014.01.040

[11] Labbé, J. (2006) L'Hydrogène électrolytique comme moyen de stockage d'électricité pour systèmes photovoltaïques isolés. École Nationale Supérieure des Mines de Paris.

[12] Tijani, A.S., Yusup, N.A.B. and Rahim, A.A. (2014) Mathematical Modelling and Simulation Analysis of Advanced Alkaline Electrolyzer System for Hydrogen Production. Procedia Technology, 15, 798-806.

https://doi.org/10.1016/j.protcy.2014.09.053

[13] Ulleberg, Ø. (2003) Modeling of Advanced Alkaline Electrolyzers: A System Simulation Approach. International Journal of Hydrogen Energy, 28, 21-33. 
https://doi.org/10.1016/S0360-3199(02)00033-2

[14] Oualid, M. (2011) Production de l'hydrog Lne à partir des énergies renouvelables.

[15] Ngoh, S.K. and Njomo, D. (2012) An Overview of Hydrogen Gas Production from Solar Energy. Renewable and Sustainable Energy Reviews, 16, 6782-6792. https://doi.org/10.1016/j.rser.2012.07.027

[16] Dw, M. and Yakubu, D. (2011) Estimation of Mean Monthly Global Solar Radiation in Yola-Nigeria Using Angstrom Model.

[17] Ursúa, A., et al. (2016) Integration of Commercial Alkaline Water Electrolysers with Renewable Energies: Limitations and Improvements. International Journal of $\mathrm{Hy}$ drogen Energy, 41, 12852-12861. https://doi.org/10.1016/j.ijhydene.2016.06.071

[18] Akpinar, E.K. and Akpinar, S. (2005) An Assessment on Seasonal Analysis of Wind Energy Characteristics and Wind Turbine Characteristics. Energy Conversion and Management, 46, 1848-1867. https://doi.org/10.1016/j.enconman.2004.08.012

[19] Dai, J., et al. (2016) Research on Power Coefficient of Wind Turbines Based on SCADA Data. Renewable Energy, 86, 206-215. https://doi.org/10.1016/j.renene.2015.08.023

[20] Shen, X., et al. (2018) Experimental Study on the External Electrical Thermal and Dynamic Power Characteristics of Alkaline Water Electrolyzer. International Journal of Energy Research, 42, 3244-3257. https://doi.org/10.1002/er.4076

[21] Kiaee, M., et al. (2013) Utilisation of Alkaline Electrolysers to Improve Power System Frequency Stability with a High Penetration of Wind Power. IET Renewable Power Generation, 8, 529-536. https://doi.org/10.1049/iet-rpg.2012.0190 


\section{Nomenclature}

\section{Roman}

$A \quad$ Area of electrode, $\mathrm{m}^{2}$;

$\Delta G \quad$ Gibbs free energy, J/mol;

$F \quad$ Faraday constant, $96485 \mathrm{C} / \mathrm{mol}$;

NHPSD National Higher Polytechnic School of Douala;

$P_{\text {turbine }} \quad$ Turbine power;

$Q \quad$ Volume flow rate, $\mathrm{Nm}^{3} / \mathrm{h}$;

$T \quad$ Temperature, K;

$V \quad$ Cell voltage, $\mathrm{V}$;

$V_{\text {wind }} \quad$ Wind velocity;

$Z \quad$ reference altitude;

$Z_{\text {wind }} \quad$ Altitude at higher of rotor;

$Z_{0} \quad$ Rugosity of site;

$r \quad$ Ohmic resistance parameter, $\Omega \mathrm{m}^{2}$;

$s \quad$ Coefficient for overvoltage on electrodes, $\mathrm{V}$;

$t \quad$ Coefficient for overvoltage on electrodes, $\mathrm{A}^{-1} \mathrm{~m}^{2}$;

$z \quad$ Number of electrons.

\section{Subscripts}

$\mathrm{H}_{2} \quad$ Hydrogen gas;

$\mathrm{H}_{2} \mathrm{O} \quad$ Water;

$\mathrm{O}_{2} \quad$ Oxygen gas;

rev Reversible;

act Activation;

Ohm Ohmique;

$\eta_{F} \quad$ Faraday efficiency.

\section{Acronyms}

AC Alternative current;

DC Direct current;

$\mathrm{KOH}$ Potassium hydroxide;

$\mathrm{Kw} \quad$ Kilowatt;

Matlab Matrix laboratory;

PV Photovoltaic. 